\title{
Organizational Change: An Emerging Need for Survival and Success
}

\section{Surendra B. Bharijoo}

THE ONLY CERTAINTY IN MODERN organizational life is countless change which is inevitable. It is increasingly common to hear and read about rapid pace of change in the world around us. The rapid pace of change in the modern world has been influencing organizational functioning and their managers. Managers can no longer be successful if they are unaware of the need for adaptation and unable to bring about changes in their organizations and their method of management. Hence, organizations of all types and roles require internal changes. Such changes may be required in the attitude and values of organizational members, the patterns of the behavior employed by organization members in dealing with one another, the structure, strategy of the organization or the technology used or any combination of these factors.

An organization not being capable of adjusting with changes in time and situation is sure to go out of market or existence. To keep up the survival, each organization requires coping with dynamics of the society. Organization is to work in society. Changes around society will also influence organization.

People perceiving the changes benefiting them and suiting their interest and goals, will be accepting and supporting those changes. But if those changes are perceived by people uncomfortable and controversy to their interest and goal, will be rejected by them. Managers have to play vital role to deal with such protests and rejection of people against changes in organization.

\section{Nature of Change}

Organizational change refers to the changes in organization-structural relationship, work/job responsibility, attitude and behavior, values and norms, rules and regulation etc. O. Jeff Harris viewed that change within an organization calls for a modification of the relationships, responsibilities or behavior of individuals who are members of the organization. Thus, organizational change indicates adjustments, modifications and alterations needed to carry out in relation to attitude and outlooks of organizational members, work relationships and responsibility, structure and procedures and inter-personal dealings.

On the basis of nature of change, it can be classified into two internal change and external change. Internal change refers to the changes in management style, resource mobilization, tools equipments, machinery, methods, technology, techniques used, process and procedures and organizational structure. External change refers to the changes in economy, social structure, government policies, location, acts and regulations, science and technology, political changes and labor market etc.

Modern organizations are open systems because both internal and external factors and forces are related to its workings. Higher performance, acceptance of new technologies, cooperation and support and decreased turnover and scrap are the common objectives of organizational change. Organizational changes are expected to bring about changes in organizational structure and procedure to suit the prevailing environment, and in working 
behavior patterns of human resources.

\section{Causes of Need of Organizational Change}

1. Changes in environment necessitate organizational change. Change in environment may result due to:

* Economic and market changes

* Technological changes

* Legal/political changes

* Resource availability changes-money, materials and human resources, market changes.

2. Changes in managerial level-human resources also necessitate organizational changes due to:

* Retirements of managers at different levels due to age bar or service bar as per the prevailing rules and regulation or, terms and condition of the job.

* Promotion of junior level managers to higher level.

* Demotion/transfer/long leave (more than one year) or on training/study leave.

* Dismissal or lay off from the job of the managers.

* Resignation or turnover of managers from company service.

Whenever post of the manager (s) of any level remains vacant, a replacement is to be made. But each manager has got his/her own management style, philosophy, management approach, value and attitude. So, situation arises to bring necessary changes in organization to suit the replacements.

3. Deficiency in present organization: Because of the short-comings, defects, duplication of work, resource, time and efforts or deficiencies in the organizational structure, working procedure, management process; there may result lack of cooperation, increasing conflict, decreasing productivity, increasing cost and scrap losses, barriers in communication process. All these hinder attainment of target/goals of the department/ group/ organization. As such, adjustments, modifications or alteration are to be carried out in organization.

4. Check the growth of inflexibility: Each organization desires to advance, grow and develop. Hence the organization should achieve flexibility to meet the growth and development needs. Leaders/managers constantly work for making the organization dynamic and flexible to achieve growth and development. So whenever experiences or foresees inflexibility, organizational changes are to be carried out. Changes under such circumstances benefit the organization as a whole.

Because of above causes, organizational changes can take place in all, some or any of the following internal changes:

1. Employee goal changes

2. Work/job technology changes

3. Organizational structure changes

4. Organizational climate changes

5. Organizational goal changes. 
3. Basic Change Process in Organization:

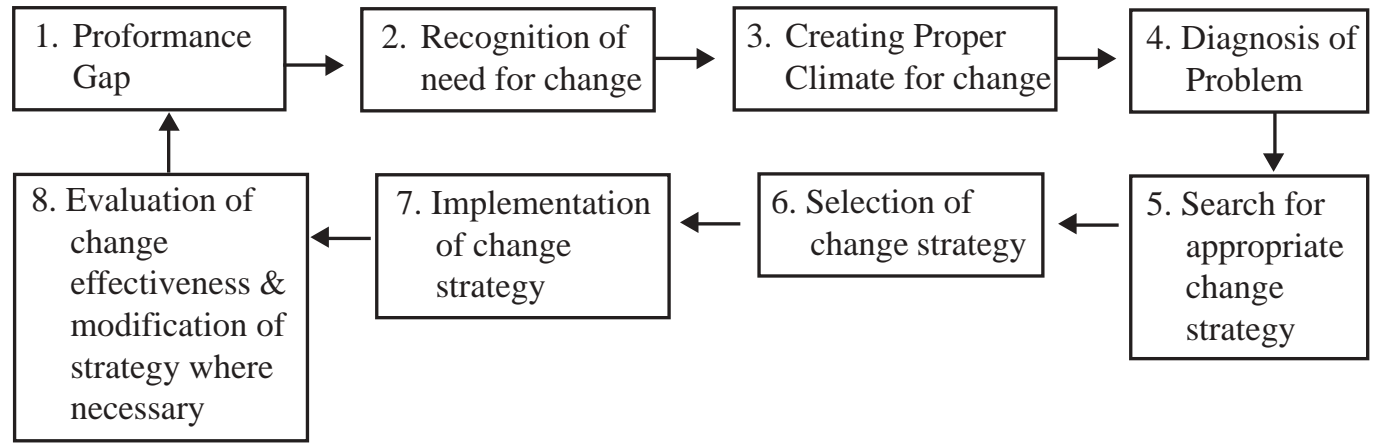

\section{Stages/ Methods and Management of Organizational Change}

1. Identify the problem.

2. Creating proper environment.

3. Analysis and diagnosis of problem.

4. Plan to change.

5. Implementation of change.

6. Follow back or feedback.

Managing the change is a challenging task. To make management of change successful and effective, organization needs to go carefully different / stages / methods / strategies discussed below.

1. Identify the problem: Managers are required to be well familiar with organizational problems which may be either internal or external in nature. In other words, performance gap indicates clearly that there exist organizational problems. Performance gap is clearly visible in terms of decreasing productivity, decreasing profitability and sales and increasing labor turnover and absenteeism. Once the mangers identify the nature and causes of organizational problems, they will then realize the need for organizational changes in order to solve the organizational problems.

2. Creating proper / favorable environment: In this stage/ process, the managers work for creating favorable environment in organization by making people realized for need for organization changes for betterment of people and organization. If positive attitude or support of organizational people could not be created in advance, people do protest the sudden change, hindering a lot for effective implementation of planned changes. So there is need of being involved in the process of creating proper climate for change. Hence self realization of managers for need for organization changes is not sufficient rather also need of letting other people realized and convinced of such necessity.

3. Analysis and diagnosis of problem: Managers through continuous study and analysis, involve in diagnosing the basic nature of performance gap and find out its causes. Sufficient information and data about organization problems are collected through the use of different diagnostic techniques-interview, questionnaires, observations etc. Managers need to devote time and efforts in this process to search for different alternatives after having carried out detailed discussion, consultation and well thinking if necessary, even taking help of specialists and resource persons. Each alternative should be evaluated in terms of its costs and benefits. 
4. Plan to change: This is the crucial process. Managers in this process prepare a thorough plan and program for organizational change, explaining clearly what changes, how changes and when changes are to be carried out. Such changes relate to tasks, people structure and technology of the organization. Structural changes may call for reorganizing the departments /divisions / sections / subsections, re-defining the span of control, delegation of authority, decentralization etc. Tasks changes include job specialization, job enrichment, job redesigning, job enlargement, job redefining and changes in working relationship. Technological changes include changes in production process, new product, and product modification, a different system of quality control, new employment and selection process. Changes relating to people include training and management development programs, promotion policy, HRM policy and other schemes to motivate people in organization. Considering the nature of organization changes proposed, appropriate strategy (ies) should be selected while planning to change.

5. Implementation of change: Managers do have a challenging task of implementing plan and programs of changes. Plan may have been well thought and sound but may not be implemented due to various reasons. Hence, after having prepared plan for change and selection of appropriate strategy, manager's responsibility to implement those, have to be discharged with a lot of care, alertness and patience. A lot of problems, protest, pressure, control, are in the way, hindering effective implementation of plan for changes. Managers should succeed in overcoming with such hindrances.

6. Follow or feedback: Managers should also involve in evaluating the effectiveness of organizational changes introduced. Such evaluation and assessment must be carried out during and after implementation of plan of changes by managers and other parties concerned to confirm the success. If such changes are not helping to attain the goals/objectives or not benefiting the organization, such changes are not positive. Then, such changes are none-effective to organization. It is therefore follow up or feedback stage calls for collection of adequate information and data to do an objective evaluation of any alternation, adjustment and modifications which are felt necessary during thorough discussion and consultation, then such are done carefully to confirm attainment of good result.

\section{Approaches or Strategies for Organization Change}

The success and failure of efforts to bring change in organization is determined by basically identification of organization problems, creating favorable climate, diagnosing the problems and selections of appropriate strategy. In other words, the planned changes are sought through following three Strategies/Approaches:

$\Uparrow$ Structural changes S/A

$\Uparrow$ Technological change S/A

$\Uparrow$ Value centered change S/A

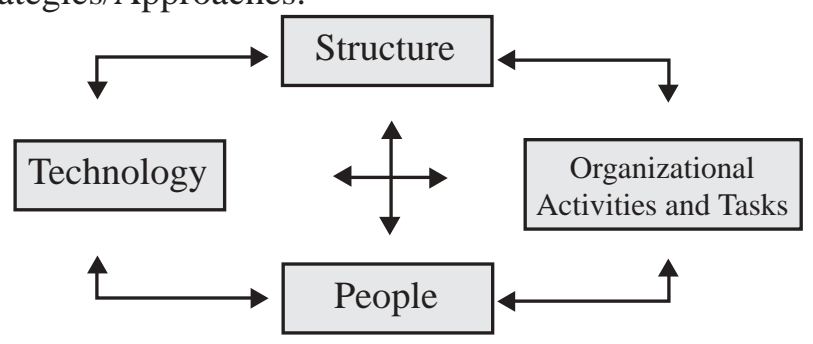


The above strategies/ approaches are found interacting with organizational functioning, activities and tasks.

Structural approach / strategy to change: Organizational change can be sought by bringing changes in the structures of the organization. Structural changes can be done by followings:

鮊 to change the nature of task or work structure to achieve specialization and rationalization.

舅 to change the basis of departmentalization ( functional departmentalization to product / geographical departmentalization )

期 to redefine or clarify in details about role and job descriptions.

舅 to change span of control and chain of command-increasing or decreasing level (s)

fot to bring changes in rules, regulations, policies, procedures and systems of organizations.

舅 to bring change in mechanisms of coordination, integration and control.

解 to bring change in delegation of authority or power structure and relationship-centralization to decentralization or vice versa.

This sort of change strategy is very much popular. The main objective of structural change is to goal-oriented efforts convenient and creating a condition of rewarding system. The basic assumption of this strategy is that human behavior, performance and effectiveness are basically determined by organizational or work structure.

Technological approach / strategy to change: This approach / strategy calls for change and alterations in existing technology of works and production of the organization. Changes in work / production technology result changes in work environment. Such changes may take the following forms.

撸 to change the technology, methods of works to bring changes in human machine relations. It is also called as Human factors engineering.

to to replace or change the nature of machines, tools and equipment used in performance of works, which may result low cost, fast work and quality improvements.

鿬 to replace or alter the entire production process or technology-manufacturing system-to change assembly line.

䧃 to bring changes in engineering process and chemical formula such as to use computer system, automatisation or replace labor intensive system to capital intensive system.

The main objective of technological strategy is to achieve improved production / work technology and get result of higher productivity, smooth operation and low cost of production.

Value (People) centered approach / strategy: This strategy / approach is aimed at bringing changes in thinking, feeling and action of organization people. The basic assumption of this strategy is that changes in motivation, attitude, skills and competency of people, necessitate changes in people's thinking, feeling and actions. Moreover, organizational behavior and organizational effectiveness are specially determined by organizational members, performances and its characteristic. If people could be changed, then it can be expected that they would work hard to attain organizational goal.

People centered approach to change may take different forms like: 
fit knowledge, skills, proficiency and competency improvements through training \& management development

(f) changes to bring communicational effectiveness.

changes in decision making process to hit mind and attitude of people towards willingness to work and high morale.

䧃 socialization of people as company man and company woman.

The selection of appropriate strategy is required to depend upon nature and causes of changes, resources available and people attitude and support for such changes.

\section{REFERENCES}

Agrawal, Govind Ram. 2001. Organizational Behavior in Nepal. Kathmandu: M. K. Publishers and Distributors.

Arnold, Hugh T. and Daniel C. Feldman. Organizational Behavior. McGraw-Hill International Editions. McGraw- Hill Book Company.

Beer M. Organizational Change and Development: A System View" Glenview, IL; Scott, Foresman.

Drucker, Peter F. 1988. The Coming of the New Organization. Harvard Business Review, (January- February): 45.

Dwevedi, R. S. 1997. Human Relations and Organizational Behavior: A Global Perspective, 4th ed. McMillan India Limited.

Huse, Edgar. 1975. Organizational Development and Change. West, St. Paul, Minn.

Kast and Rosenzweig. Organization and Management: A Systems Approach, International Student ed. Tokyo: McGraw - Hill Kogokusha, Ltd.

Kelly, Joe. 1987. Organizational Behavior: Its Data, First Principles and Application, first Indian Reprint. Delhi: Surjeet Publications.

Kimerly, John R. and Warren R. Nielsen. 1975. Organizational Development and Change in Organizational Performance. Administrative Science Quarterly: 191 - 206.

Luthans, Fred. 1989. Organizational Behavior, McGraw-Hill International ed. McGraw - Hill Book Company.

Mitchell, Terence R. and James R. Larson. Jr. People in Organizations: An Introduction to Organizational Behavior, 3rd ed. McGraw- Hill Book Company.

Newstrom, John W. and Keith Davis. 1996. Organizational Behavior: Human Behavior at Work, 9th ed. Tata McGraw - Hill Edition.

Robbins, Stephen P. 1999. Organizational Behavior, 8th ed. New Delhi: Prentice - Hall of India. 